Fertility regulation during human lactation

\title{
PROFESSIONAL ATTITUDES TO BREAST-FEEDING
}

\author{
URSULA LIEBRICH \\ Christian Medical Commission, Geneva
}

We have heard a lot about the promotion of sales of baby food, but we have never analysed the population's readiness to accept such foods, and how that acceptance comes about. Nor have we analysed the role of the doctors or the health professionals. What is it or what should it be?

About a year ago we carried out a study in London on the intention to breastfeed and the success of mothers in breast-feeding (Liebrich \& Morley, 1976), at the same time analysing the attitudes of the staff attending these mothers, who should have helped the latter in their breast-feeding. Table 1 shows a trend in the answers given by women who intend to breast-feed disagreeing with such statements as 'Nowadays it is no longer necessary to put up with the mess of breastfeeding when easily prepared milks are available' and agreement (among the same group of mothers) with such statements as: 'Breast milk is the best food for a baby under four months'.

\section{Table 1}

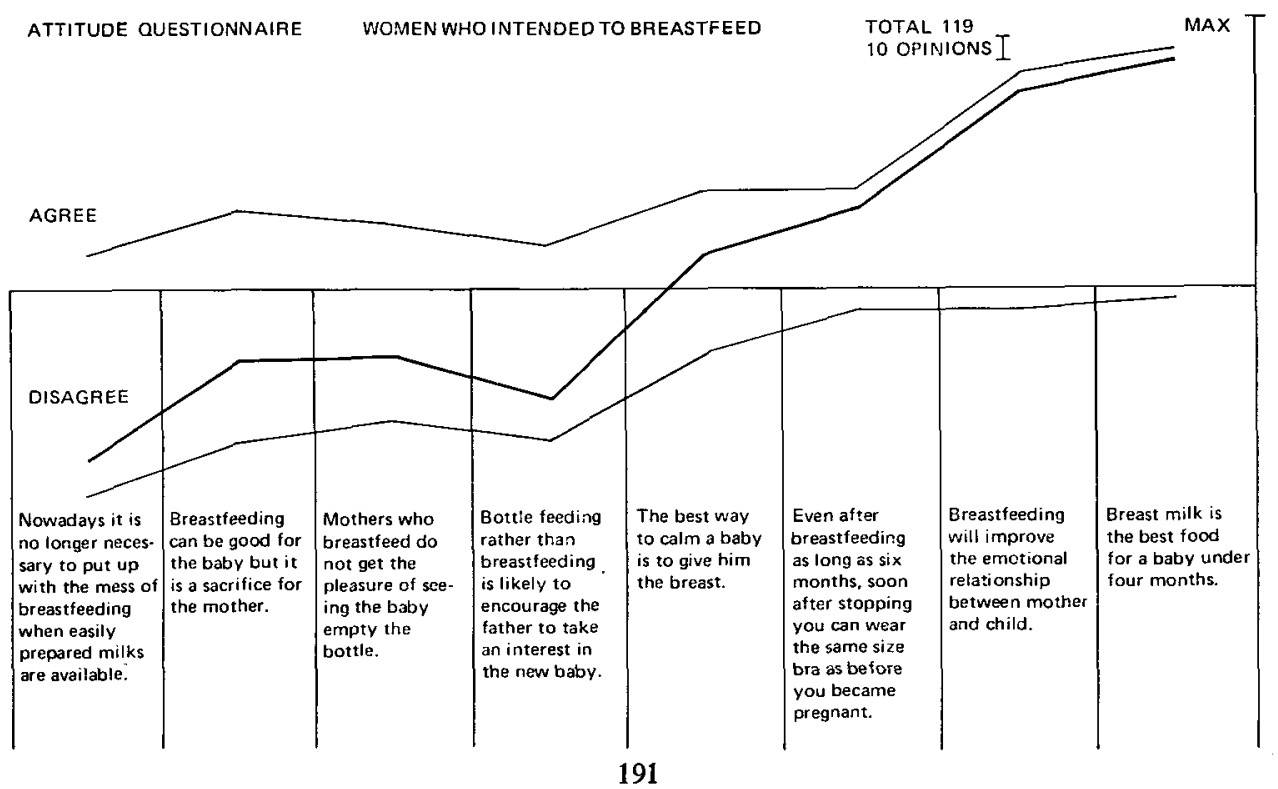




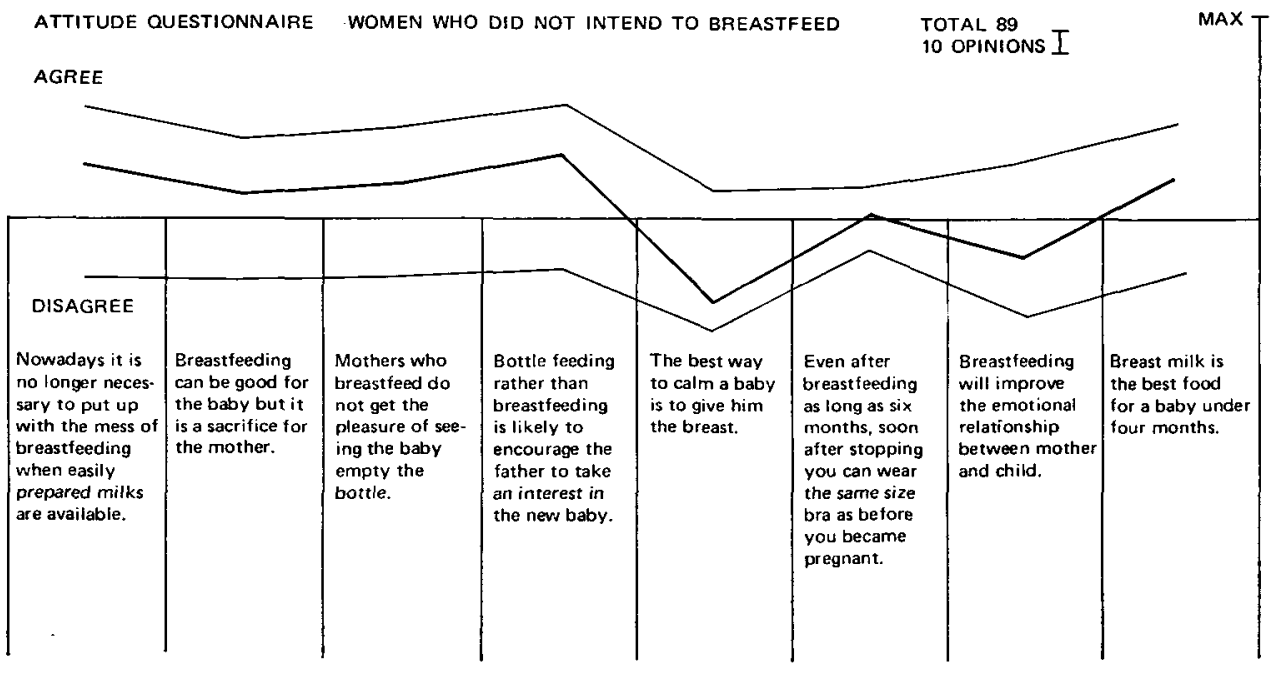

The attitudes in women who did not intend to breast-feed were almost completely the opposite (Table 2), with the majority of those women agreeing that it is no longer necessary to breast-feed a baby nowadays.

We covered some rather controversial topics with the staff (Table 3). For instance, the majority of health workers in a maternal clinic agreed with the statement: 'Health workers must dissuade the mother from having her baby to suckle

Table 3

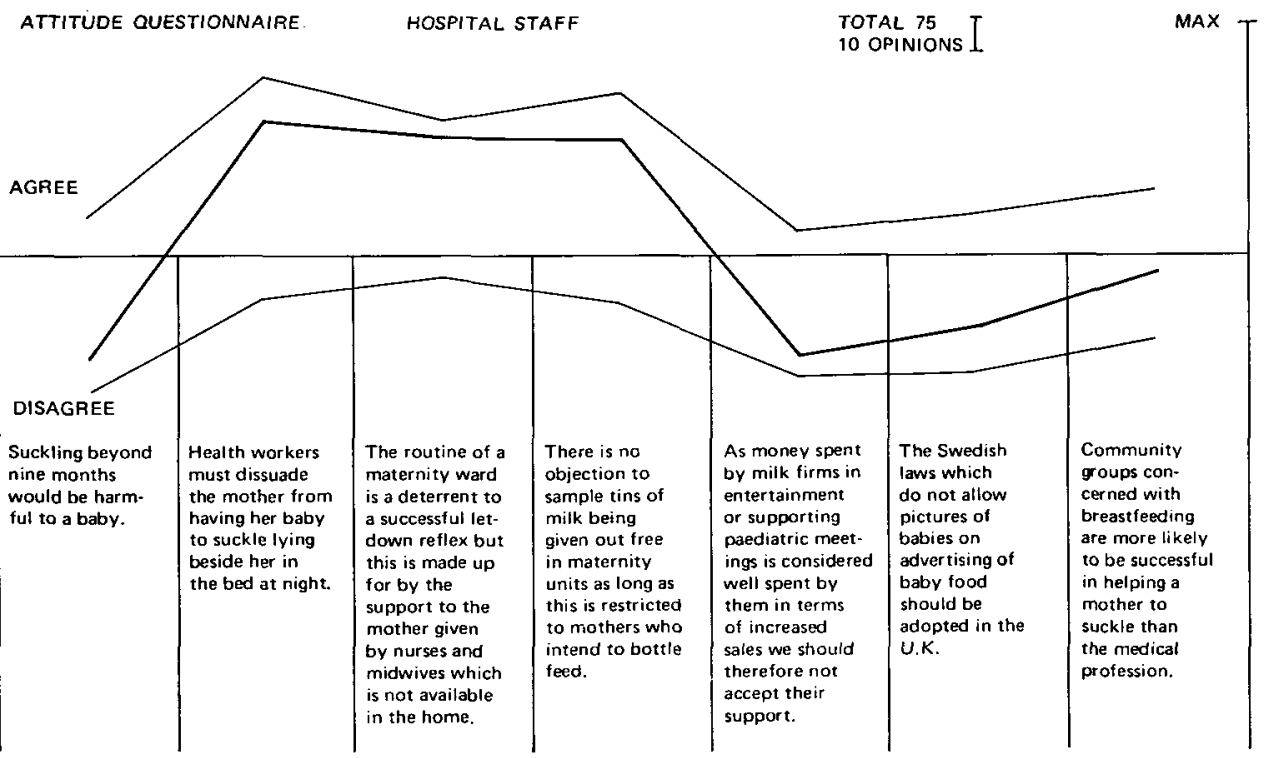


lying beside her in bed at night'. These health workers said that of course the mother cannot have the baby lying with her, it would be most unhygienic.

The majority of nurses were in agreement with the following statement: 'The routine of the maternity ward is a deterrent to a successful let-down reflex but this is made up for by the support to the mother given by nurses and midwives which is not available at home'. On the other hand, most community-medicine trained doctors disagreed with that statement (Table 4).

\section{Table 4}

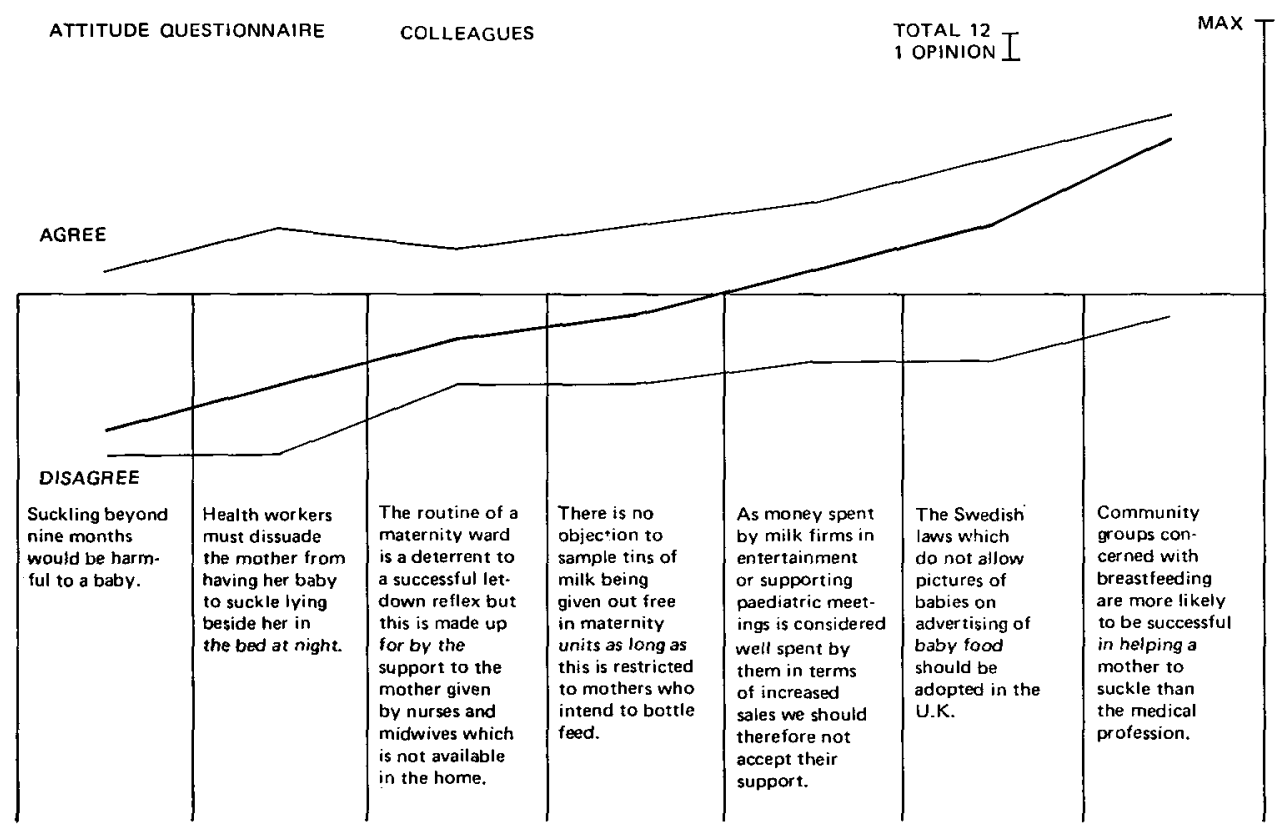

Recently a more in-depth study on attitudes of health staff was carried out in a London district (Kurtz, 1976), finding that $30 \%$ of all the staff concerned with maternal and child health in that district agreed with the proposition that breastfeeding is no longer an important medical issue.

This should make us reflect a little. Most of us who have been through medical school have had the experience of hearing nothing about breast-feeding, although we have heard about formulae and how to mix them. The doctor's role is supposed to be health care, but in fact his training is for disease care. Therefore, a normal phenomenon such as breast-feeding does not come much into the curriculum.

We have exported our health services all over the world - despite the fact that they may not be appropriate to other societies-and with the exporting of our health services have gone many of our attitudes too. The trend to separate mother and baby has gone on for centuries, in European societies. No other society has used things like a pram, or developed a fashion which makes it almost impossible for a mother to feed her baby, yet these things can be found in our society for 
several centuries. Wet nurses, for instance, are a European invention. They preceded the baby food industry which, in fact, grew out of this concern of our society to get women away from their babies.

When we talk about women's liberation we should also remember that the woman's role is to have successful motherhood, a performance which cannot be equalled by men. Probably making women beautiful for men is a consequence of what men want for women's existence. The breast has been looked upon in our society as an erotic symbol for men to play with, not for babies to feed from. This is one of the fundamental changes we ought to try to make in attitudes.

\section{References}

KurTZ, Z. (1976) Medical and Nursing Staff Attitudes to Breast-Feeding. MSc. Thesis, London School of Hygiene and Tropical Medicine.

Liebrich, U. \& Morley, D. (1976) Attitudes towards breast-feeding. J. trop. Pediat. Envir. Child Hlth. 22, 31. 